Western University

Scholarship@Western

Health Studies Publications

Health Studies Program

$9-2005$

\title{
Fostering Interactions: The Networking Needs of Community Health Nursing Researchers and Decision Makers
}

\author{
Anita Kothari \\ The University of Western Ontario, akothari@uwo.ca \\ Nancy Edwards \\ University of Ottawa \\ Susan Brajtman \\ University of Ottawa \\ Barbara Campbell \\ University of Prince Edward Island \\ Nadia Hamel \\ University of Ottawa \\ See next page for additional authors
}

Follow this and additional works at: https://ir.lib.uwo.ca/healthstudiespub

Part of the Medicine and Health Sciences Commons

Citation of this paper:

Kothari, Anita; Edwards, Nancy; Brajtman, Susan; Campbell, Barbara; Hamel, Nadia; Legault, Frances; Mill, Judy; and Valaitis, Ruta, "Fostering Interactions: The Networking Needs of Community Health Nursing Researchers and Decision Makers" (2005). Health Studies Publications. 9.

https://ir.lib.uwo.ca/healthstudiespub/9 


\section{Authors}

Anita Kothari, Nancy Edwards, Susan Brajtman, Barbara Campbell, Nadia Hamel, Frances Legault, Judy Mill, and Ruta Valaitis 
Fostering Interactions: The Networking Needs of Community Health Nursing Researchers and Decision-Makers

By

Anita Kothari, $\mathrm{PhD}^{1}$; Nancy Edwards, RN, $\mathrm{PhD}^{2}$; Susan Brajtman, RN, $\mathrm{PhD}^{2}$; Barbara Campbell, RN, PhD(c) ${ }^{3}$; Nadia Hamel, RN PhD(c) ${ }^{4}$; Frances Legault, RN, $\mathrm{PhD}^{2}$; Judy Mill, $\mathrm{RN}, \mathrm{PhD}^{5}$; Ruta Valaitis, $\mathrm{RN}, \mathrm{PhD}^{6}$

Please direct correspondence and requests for reprints to the first author:

1. Assistant Professor

Bachelor of Health Sciences Program

University of Western Ontario

2319 Somerville House

London, Ontario

N6A 3K7

akothari@uwo.ca

2. School of Nursing

University of Ottawa

3. School of Nursing

University of Prince Edward Island

4. Centre for Global Health

University of Ottawa

5. Faculty of Nursing

University of Alberta

6. School of Nursing

McMaster University

Clinical Consultant, City of Hamilton Public Health and Community Services PHRED program. 


\begin{abstract}
The purpose of this study was to determine the current extent of linkages among Canadian community health nursing researchers and decision-makers and to identify perceptions around the structure and function of potential networks. A qualitative research design was utilized to develop common themes across focus groups, a workshop, and key informant interviews. Findings suggest that there is a need for a formal community health network to provide an efficient and timely means to link the expertise required to tackle complex community health policy problems, and to create supports for advancing community health science with relevant and high quality research.
\end{abstract}

Key words: knowledge translation, community health, decision-makers, networks, policy making, health services research, nursing, research 


\section{Fostering Interactions: The Networking Needs of Community Health Nursing Researchers and Decision-Makers}

\section{Introduction}

Evidence-based practice (EBP) and evidence-based policy-making (EBPM) have been prominently positioned in the health domain. Evidenced-based practice emphasizes the need to critically analyze and then incorporate the latest research findings into day-to-day clinical activity (Sackett et al, 1997). When scientific findings are not available, evidence may come in the form of consensus statements developed by experts in the field, or from other sources. Evidenced-based policy-making emphasizes the need to use research findings in developing health programs and policies. Research findings can be balanced with population values and needs (Gray, 2004). EBP and EBPM are being promoted to ensure that clients and communities receive the most effective care, leading to improved health outcomes. Professional networks may be a promising tool to support EBP and EBPM (Lave and Wenger, 1991; Kirkpatrick, 1995, Russell et al, 2004). The purpose of this study was to conduct a networking infrastructure needs assessment with community health nursing researchers and decision-makers.

Evidence-based nursing practice may be ideal, but findings in the nursing literature identify numerous barriers to achieving this clinical standard. These include such things as lack of authority to change practice, lack of support from administration, constraints in terms of time and human resources, limited access to research, and the lack of research understanding among some diploma level nurses (Funk, 1991; Estabrooks, 1999). Evidenced-based policy-making is also associated with challenges. Innvaer and colleagues (2002) conducted a systematic review of health policy-makers' perceptions of their use of evidence. The authors identified the following as barriers to EBPM: the lack of personal contact between researcher and user, a mutual mistrust between researcher and user, struggles over power and budgets, and the lack of timely or relevant research. Innovative methods of translating research findings to the users of information continues to be a significant challenge (Dobbins, Ciliska, Cockerill, Barnsley, and DiCenso, 2002; Rynes, Bartunek and Daft, 2001).

\section{Background: Strategies to Overcome Challenges}

Two strategies are being developed to overcome the challenges of evidence-based approaches in practice and policy-making: 1) the utilization of a knowledge broker, and 2) the active fostering of interactions between producers and users of research studies. In addition to the producer and user of knowledge, a third player, the knowledge broker, is emerging in the role of translating research for practice or policy-making. The knowledge broker concept is borrowed from the private sector, where the role involves stimulating innovation in organizations (Hargadon \& Sutton, 2000). For EBP and EBDM, the broker is responsible for contextualizing research findings for local applicability, subsequently interpreting research findings for the specific needs of the user. These tasks might include: monitoring and identifying relevant research, synthesizing research studies, disseminating findings in reader-friendly formats (e.g., policy summary, presentations), or guiding the implementation of research findings (CHSRF, 2004). The empirical evidence supporting the knowledge broker in health is minimal.

Consequently, organizations like the Canadian Health Services Research Foundation, and the International Development Research Centre, have recently launched projects to evaluate the value of a knowledge broker. 
The second strategy encourages interactions between researchers and users. This strategy acknowledges that researchers and decision-makers come from different communities and use different language and methods of communication (Caplan, 1979). Narrowing the divide between the two communities is assumed to increase the sensitivity of each community to the other's position and professional. The expectation is that interactions can promote EBP and EBPM (Lomas, 2000; Lavis et al, 2003; St. Croix, 2001). Early empirical work by Huberman (1994) characterized these interactions as "linkages and exchanges." Linkages refer to the idea that the interactions might be a result of formal relationships between researchers and users. Equally significant, however, are the informal linkages between people. Exchanges, on the other hand, underline the necessity of two-way communication between researcher and user. The general premise is that in order for interactions to be effective, linkages and exchanges ought to be frequent, intense and sustained. In this way research can be incorporated into the professional activities of health professionals.

In general these two strategies have evolved as separate streams. We suggest, however, that formalized professional networks might be a way to incorporate both strategies (knowledge brokering and interactions) and, at the same time, support evidenced-based activities. The Canadian Health Services Research Foundation, as leaders in knowledge brokering and transfer, state that interactions between decision makers and researchers can result in the development of supportive environments that foster mutual learning. Interactions represent the crux of a number of network concepts, such as communities of practice, advocacy coalitions, strategic alliances, or internal knowledge management networks; these concepts were originally developed for the purposes of political influence or knowledge dissemination. The World Health Organization (1998, p.16) defines a network as:

'...a grouping of individuals, organisations and agencies organised on a non-hierarchical basis around common issues or concerns, which are pursued proactively and systematically, based on commitment and trust'

Networks are seen as a way to solve complex problems (Hill, 2002). A network can facilitate the sharing of resources, access to expertise and the adoption of technologies (Hill, 2002). Networks might promote interactions between individuals that might not have otherwise occurred. Social interactions can contribute to the translation of scientific findings thereby facilitating support for EBP (Lave and Wenger, 1991; Rogers, 1995). In addition, new knowledge may be created as individuals interact. Through network linkages decision-makers can flag priority issues, leading to more timely applied research findings for EBPM. Researchers can ensure that their own research agendas meet decision-makers' needs. Information brokers can play a key role in a network by taking on the important task of network animateur to foster interactions. In other words, by providing the appropriate structure and content, we suggest that interactions can be promoted so that knowledge will be developed, and relationships - where knowledge is shared and stored - can be nurtured. A health-focused network could inform the research agenda, help set priorities for research, and complement and strengthen existing approaches to seeking "just-in-time" information and evidence for decision-making.

To summarize, knowledge brokers and interactions between the producers and users of knowledge are being promoted to support EBP and EBPM. Networks provide an opportunity to consolidate these strategies within a common infrastructure. The research question of interest was: what are the perceived benefits and challenges associated with a network for community 
health professionals? A qualitative research design was used to understand the extent of current linkages, both formal and informal, among community health nursing researchers and decisionmakers, and to identify perceptions around network structure and function. Our approach is unique in that decision-makers and researchers were brought together to discuss the issues from both points of view. Thus, the findings reflect a deliberative process. This study is part of a larger program of research exploring the effectiveness of networks as knowledge translation tools.

\section{Methodology}

Research Design: Participants discussed their views through focus groups, a workshop and key informant interviews in the fall of 2003. The consecutive nature of the sessions - focus groups, followed by the workshop, followed by key informant interviews - was important. The responses from one session informed the next session through the development of more useful probes to support the interview guide. The qualitative research approach permitted further exploration of issues as they arose during data collection. For example, we obtained immediate feedback about possible mechanisms to strengthen the current linkages. Ethical approval for the project was obtained from the University of Ottawa's Research Ethics Board.

Sample Selection and Data Collection: The population of interest for this research included decision-makers and community health nursing researchers. We defined decisionmakers in community health as program managers and senior administrators working in health services delivery organizations, and those involved with policy development in governmental, non-governmental organizations, educational and professional associations. Community health nursing researchers were defined as researchers working on issues relevant to the areas of home health nursing and public health nursing.

The project was situated in the Canadian context. In order to inform the research purpose, project participants had to be knowledgeable about current Canadian structures and issues within community health. Leaders in the field (i.e., prominent researcher or practitioner) or in their organization (i.e., senior level administrator or bureaucrat) were the population from which participants were recruited. Thus, leaders in community health nursing researchers and decision-makers were purposively sampled. Participants had to have been working in their organization for at least six months in order to participate in the study.

Using a community health frame of reference, participants were asked to: a) define the role of a network; b) identify their own networks for particular purposes (e.g., educational development or research); c) discuss how they initiate and maintain their contacts; d) describe their formal linkage mechanisms at the organizational level; e) discuss challenges associated with networks; f) brainstorm system level supports for a hypothetical network structure; and g) discuss the role of technology with respect to networks.

\section{Focus Groups:}

As a data collection tool, focus groups allowed researchers and decision-makers to engage in a common discussion. The focus groups were planned to coincide with professional meetings where community health leaders were known to be attending. All participants were invited to participate in a research-oriented focus group that was not related to the meeting at hand. Following each focus group, members of the research team who were present informally debriefed on the emergent ideas and used this information to guide modifications to the focus 
group questions. The research team used debriefing methods (Cresswell, 1998) to enhance the credibility of findings. Given the diversity of each team member's backgrounds and professional training, the investigators brought different perspectives to the debriefing sessions. Focus groups were facilitated by one of the principal investigators.

The first focus group was at a Public Health Research Education and Development (PHRED) annual meeting in Ontario. Nine participants attended, consisting primarily of community or public health clinical nurse specialists with health departments in Ontario and Directors of PHRED programs in Ontario.

The second focus group was held during the Canadian Association of Schools of Nursing conference. All participants attending a Graduate Studies Forum during the conference were invited to attend. Twelve participants attended, including Directors of Nursing Graduate Studies Programs and Deans or Directors of Schools of Nursing from across Canada. Although not all participants had a community health clinical or research background, they were seen as having an important "pulse" on emerging issues. Questions around networking for this group were, therefore, of a more general nature.

The third focus group was also held during the Canadian Association of Schools of Nursing conference, at a designated concurrent session. All participants were invited, and ten participants attended, consisting primarily of university/college nursing educators from across Canada. Participants were not necessarily coming from a community health perspective but most, by virtue of their voluntary attendance, had a specialized interest in community health nursing.

The three focus groups were taped and transcribed verbatim to ensure accuracy (Patton, 2002). In addition, a member of the research team assumed the role of note-taker in each focus group session, capturing the discussion and "side" conversations or comments that may not have been audible on the tape recorder. To ensure a breadth of issues from the focus group data, the principal investigators independently conducted a content analysis of the transcripts, notes taken during the focus groups, and the debriefing notes for emerging themes (Patton, 2002). Following this, some members of the research team came together to discuss the identified themes as well as to identify themes that did not surface. The implication of these findings was also discussed (Denzin and Lincoln, 2000).

\section{Workshop:}

Thereafter, an invitational workshop was held to ensure geographic, linguistic and decision-maker representation. A participant invitation list was drafted through contacts and organizations already known to and/or recommended by the research team. Nineteen community health nursing decision-makers and researchers from across Canada attended the workshop. The workshop began by asking generally the same questions that were asked of focus group participants. The additional time was spent encouraging participants to develop their vision of a networking infrastructure in detail. A professional moderator was hired to lead the workshop.

A research assistant acted as a note-taker during the workshop in order to capture the proceedings verbatim; the workshop was also taped. The recording was used to fill the gaps in the research assistant's proceedings. A 45-minute debriefing session was held with the research team and facilitator immediately after the workshop. Ideas identified at the session were triangulated with a more formal content analysis of the proceedings, independently done by one of the principal investigators and the research assistant. Discrepancies were brought back to the team for discussion. 
Interviews:

Finally, ten telephone interviews and one in-person interview were conducted to enable input from interested invitees not able to attend the earlier workshop. These included decisionmakers and researchers from organizations across Canada. Those decision-makers representing national organizations were asked additional questions to capture ideas about organizational networks (e.g., "How would a network help strengthen linkages between your organization and the community health nursing community?").

Notes were taken by one of the principal investigators and a research assistant during interviews with key informants. The informants' descriptions of the factors influencing networks were introduced at another team debriefing session. A content analysis of the notes concentrated on any differences in themes that emerged from these participants (rather than confirming themes identified by previous participants).

\section{Findings}

In total, 61 individuals participated in this study. Table 1 describes the number of individuals participating in each session, broken down by province. Perspectives from across Canada were captured. Individuals were purposively chosen as leaders in the field of community health - they included clinical nurse specialists with health departments in Ontario and Directors of Public Health Research Education and Development programs in Ontario, Directors of nursing graduate studies programs, Deans and Directors of schools of nursing across Canada, university and college nursing educators from across Canada, and community health nursing decision-makers and researchers. The Territories and Saskatchewan were not represented in the participant profile.

$<$ Table 1 Here - Geographical profile of participants $>$

In this paper we report on the major, common themes that emerged across the focus groups, workshop and interviews:

\section{A. The Current Range and Functions of Linkages}

Participants described formal and informal linkages or networks that they are currently engaged in or could envision for the future. A range of mechanisms was described to maintain informal networks. On one end of the spectrum were informal relationships, based on shared previous experiences (e.g., graduate training) or common research interests. Participants stressed that these linkages were maintained because they derived personal satisfaction from them; this outcome came across as more important than opportunities for future research collaboration. The frequency of exchanges ranged from regular, casual lunches to annual meetings at a conference.

At the other end of the spectrum participants described formal relationships between organizations. These included such things as representation on a committee or joint appointments with university departments. These mechanisms related to a specific purpose with regular, scheduled exchanges. As they tended to be at the organizational level, the relationships legitimized linkages that might not have otherwise been permitted to flourish. One cited advantage to this approach was that the linkage with an organization had longevity even when 
staff turnover occurred. The differences among these networks are illustrated by the following comment by a participant:

"A network for sharing purposes is totally different from a network for collaborating."

Researchers expressed relatively more comfort with networking with decision-makers at the local community level and, interestingly, sometimes at the international level where key decision-makers were easier to identify. There appeared to be less comfort and ease with networking with decision-makers within Canada at the provincial and national levels. As one participant put it:

"Networking is much easier at the local community level and gets more complex as you move away from it."

\section{B. Challenges in Effective Networking}

The challenges to linking into and sustaining a network, from an individual perspective, included factors such as lack of time, limited funds, lack of recognition in academia, difficulty in identifying the right decision-maker and uneasiness with compromising the research questions. Participants provided many ideas about how they manage to keep in touch with decision-makers, such as actively scheduling time for it, or by taking on consulting work. While there was much brainstorming around the issue, a common or "best practices" strategy did not emerge. The following quotes capture the complexity of effective networking:

"[Effective networking] requires a lot of skill and thought to pull together because of differing value systems."

"[Ineffective networking is] octopus networking - the arms get too thin and there are too many trying to do too much."

\section{The Potential Value of Networks to Evidenced-Based Practice and Decision-Making}

There appeared to be agreement that a network infrastructure could have value even though at times there was a lack of clarity expressed by participants on what the purpose of a hypothetical network would be and the subsequent form it would take. Participants viewed a network as having the potential to lead to improvements in community health policy and design by:

- Creating supports for advancing the science of community health with more appropriate and higher quality research - a research agenda informed by the needs of people who are making policy in the community health sector. As a decision-maker said: 
"Networks with researchers are one of our most important tools ... we're looking at evidence to support anything we do ... most decisions are made on economics - the lowest common denominator - as opposed to evidenced-based practices."

- Enabling EBP and EBPM - translating research into user-friendly language and clear implications for community health policy, design, and practice; brokering place to share how others use findings, and facilitate evidence-based decision-making

- Enabling more cross-community learning to foster more effective innovation e.g. through access to unpublished experience, and piggy-backing on others' experiences

- Enabling more direct access between the creators of knowledge and the users of knowledge.

- Allowing decision-makers to obtain a quick response from the community in times of crisis (e.g., SARS)

- Fostering multi-site and multi-disciplinary research and innovation. One participant noted:

"I see nursing as the hub of the wheel ... Nursing has an integrating role. Nurses can speak the language of other disciplines ... There are cardiovascular nurses, oncology nurses - a million and one of these groups - all working separately on smoking cessation. We need to bridge them. How do we get them working together?"

- Amplifying the voice of nursing within community health (by, for example, providing a venue to identify champions and leaders who have the capacity to mobilize change)

\section{Describing the Network: Emphasis on Face-to-Face and Less Emphasis on Technology}

Participants initiated discussions using face-to-face interactions as a point of reference. One respondent suggested that:

"Face to face - even if infrequent (but at least annually) because you need to know who you will work with, what the culture is - this is also what fuels passion."

There was clarity about how these interactions ought to be run, their frequency and who ought to be organizing them. Participants could easily envision what these venues might entail, as the quote below illustrates:

"Need lots of opportunities for exchange and dialogue e.g. long working lunches and dinners, and unstructured time. Start with a half-day at the beginning. Tap into events already happening - bring people in for a half-day before (e.g. hold a pre-conference meeting)."

Project participants emphasized the need for face-to-face communication at least initially to build trust. They also described challenges around face-to-face networking, such as: the travel costs involved, the time it takes out of already busy schedules, and the perception that it is inefficient (i.e., time not well used). On this last point, participants described requiring almost an attitude shift to legitimize the time and resources required for face-to-face networking. 
For the most part, the facilitators had to probe for views on technology. The phrase "electronic platform" was confusing and ambiguous for participants. There were some comments about what a discussion board or website might include, but there was also concern that those who were technologically less able would be left out of the network. It was noted that this might be a generational issue as the younger and more technologically comfortable cohort becomes established.

\section{The Expanded Role of Funding Agencies in Networks}

Surprisingly, funding agencies, such as the Canadian Institute for Health Research and the Canadian Health Services Research Foundation (CIHR and CHSRF), were perceived to play bigger roles than simply providing research dollars. Participants expected that funders would take on the role of network organizers, especially with respect to face-to-face meetings or annual conferences. In part this expectation was driven by the current need for decision-maker partnerships in various grant proposals. In addition, participants expected that funders would know the identity of the appropriate decision-makers. Furthermore, funders were seen as neutral third parties who could create a neutral meeting ground. Some even saw funders as members of the network. This quote highlights the expanded role of funders:

"The Canadian Institute for Health Research has helped on a national scale e.g. the research symposium in March 2003. It brought all kinds of people together. There was a mix of researchers and funders."

\section{Discussion}

The study findings suggest that community health nursing researchers and decisionmakers are less comfortable with certain types of linkages (e.g., national-level ones) in their current professional networks. Moreover, the study found that gaining entry into and maintaining linkages with other professionals and stakeholders can be a difficult proposition for most. Despite these challenges and other barriers, participants attached value to a network, and believed they had the potential to support multi-site and multi-disciplinary innovation. The current community health system benefits from the knowledge derived from multiple stakeholders, but the complexity of the system necessitates efficient, collaborative networks. That is, knowledge is generated through interactions among professionals and then stored in their corporate relationships as a mechanism to bridge the gap toward future work.

This study revealed some unexpected findings. While local and international links were the most commonly cited ones, links at other levels of the system (e.g., federal, and in some cases, provincial) were noticeably absent. It might be that the lack of linkages at these levels is due to the inaccessibility of decision-makers in these senior positions. Alternatively, (researcher) participants may not have actively sought or cultivated these particular contacts for their work. Perhaps there is a perception that community health research or practice is supported best with local links, and those broader jurisdictional policies or practices are less important. It is precisely this narrow lens that must widen if community health is to be strengthened across the system (Kothari and Edwards, 2003; National Advisory Committee on SARS and Public Health, 2003). Future endeavours may include establishing network links of multidisciplinary health 
partners from acute care, long term care, and community building for their unique perspectives to improve health care delivery.

Participants were able to describe the many ways that they try to maintain their networks. In doing so, it was clear that respondents did not rely on a 'tried and tested' strategy, nor did they spontaneously list common approaches. Future research might be required to evaluate and determine a best practices networking strategy for those within the educational, research, clinical and policy sectors.

Another result with fundamental implications was the way in which participants described a hypothetical networking infrastructure. Their discussions emphasized face-to-face interactions over the use of an electronic interface despite the noted lack of time and costs of personal contact. This finding is in agreement with previous literature, which emphasizes the importance of personal contact to support collaborative networks (Nohria and Eccles, 1992; Wenger et al, 2002). The finding might also suggest that this professional group may not be as comfortable with electronic interfaces or might not have access to the most efficient technology. Since there is a strong history of collaborative educational networks in Ontario with heavy reliance on distance education technology (e.g. audio-teleconferencing for the collaborative nurse practitioner programs, distance education for post-RN programs), it may be that the expressed desire for face-to-face venues reflects the novelty of researchers working closely with senior decision-makers. In considering the use of technology to support networking, therefore, one must take into account the newness of the technology and the extent to which relationship between researchers and decision-makers are new or well-established. The importance of informatics competencies cannot be understated. The U.S. Centres for Disease Control and Prevention has developed a set of public health competencies with respect to informatics. They state, among other things, that a public health professional, "Uses the media, advanced technologies, and community networks to communicate information" (O'Carroll et al, 2002). This study supports the need to consider using technology as an adjunct to personal contact. Perhaps emerging technologies, such as web conferencing media, which are used heavily in the corporate world, would be useful in the community health practice and decision-making context.

At least two significant issues were noticeably absent from the discussions. First, participants had a narrow vision of potential members of their professional networks.

Participants named community health researchers, educators, decision-makers, funders and community-based health workers as likely members of a future network. Participants did not identify other possible members of a network, such as the media, university public relations or a librarian. Perhaps we limited the participants' views by virtue of the questions asked. Nevertheless, these non-traditional colleagues could have a valuable role in supporting community health research, practice and policy-making.

As well, we noted that participants did not identify the potential of a network to lead to improvements at a health systems level. They did not explicitly make the link between interactions with colleagues or decision-makers leading to more informed policies, or more applied research, which could eventually contribute to improved health outcomes in the population. This potential benefit needs to be highlighted for community health professionals. Rather, the focus of their discussions was about networks for research or educational purposes.

This study is novel in that it deliberately brought together researchers and decisionmakers to discuss research translation and networks. The findings would be of most interest to researchers and decision-makers working in community and public health arenas. Some of the findings may be applicable to, and could serve as a model for, other nursing specialties or health 
professions that are seeking to encourage new, and strengthen existing, partnerships between researchers and decision-makers. For example, one potential area of nursing mentioned by a participant is the area of palliative care. One of the weaknesses of this study, however, is few participants had expertise in home care. Nevertheless, the findings could be used to develop networks for EBP and EBPM in other health sectors (e.g., the Health Research Transfer Network of Alberta), and perhaps inform the development of networks in other health care settings. For example, an email network for UK healthcare practitioners and researchers was initiated in 1997 (Russell et al, 2004). Our study suggests that this network could be further developed with the addition of periodic face-to-face venues to reinforce professional ties.

\section{Conclusion}

This study suggests that there is a need for a formal structure or mechanism to foster interactions between community health nursing researchers and decision-makers. Such an infrastructure could foster cross-community learning and instill a culture of collaboration. It could enable the translation of best practice knowledge into community health policies and programs resulting in an evidence based practice. For example, it could provide a venue to share how others use findings and to facilitate evidence-based decision-making in the field of community health, or it could provide innovative and supportive work tools. A community health network could provide an efficient and timely means to link areas and depth of expertise required to tackle complex community health policy problems and create supports for advancing community health science with relevant and high quality research.

\section{Acknowledgement}

The research team wishes to acknowledge and thank the Canadian Health Services Research Foundation for providing financial support for the study. Dr. Nancy Edwards holds a Chair in multiple interventions in Community Health Nursing from the Canadian Health Services Research Foundation, the Canadian Institutes of Health Research and the Ontario Ministry of Health and Long-term Care. Drs. Kothari and Mill were supported by CHSRF postdoctoral fellowships during the study.

Andrea Perrier provided research assistance during the study, for which we are grateful. Thanks are also extended to project participants for their time and input. 


\section{References}

Canadian Health Services Research Foundation. (2004) The Third community:Knowledge brokering, research, and policy. Retrieved April 8, 2005

http://www.chsrf.ca/brokering/pdf/National_Workshop_\%20Report_2004_e.pdf

Caplan, N. (1979). The two-communities theory and knowledge utilization. American behavioral Scientist, vol 22, no.3:459-470.

Community Health Nurses Association of Canada (May 2003) 'Canadian Community Health Nursing Standards of Practice.' Retrieved: January 22, 2004. http://www.communityhealthnursescanada.org/Standards\%20of\%20Practice.pdf

Cresswell, J.W. (1998) Qualitative Inquiry and Research Design: Choosing Among Five Traditions, Thousand Oaks, CA: Sage Publications, Inc.

Denzin, N.K. and Lincoln, Y.S. (2000) Handbook of qualitative research, 2nd edition, Thousand Oaks, CA: Sage.

Dobbins, M., Ciliska, D., Cockerill, R., Barnsley, J., \& DiCenso, A. (2002). Framework for the dissemination and utilization of research for health-care policy and practice. The online journal of knowledge synthesis for nursing, vol 9, no. 7: 1-12.

Estabrooks, C.A. (1999) 'Modeling the individual determinants of research utilization.', Western journal of nursing research, vol 21, no 6: 758-772.

Funk, S.G., Champagne, M.T., Wiese, R.A., Tornquist, E.M. (1991) 'Barriers to using research findings in practice: The clinician's perspective.', Applied nursing research, vol 4, no 2: 90-95.

Hargadon, A., \& Sutton, R.I. (2000) 'Building an innovation factory.', Harvard business review, vol 78, no. 3: 157-167.

Hill, C. (April 15, 2002). Network Literature Review: 'Conceptualizing and Evaluating Networks.', prepared for the Southern Alberta Child \& Youth Health Network.

Huberman, A.M. (1994) 'Research utilization: The state of the art. Knowledge and Policy.', The international journal of knowledge transfer and utilization vol 7, no 4: 13-33.

Innvaer, S., Vist, G., Trommald, M., and Oxman, A. (2002) 'Health Policy-Makers' Perceptions of their Use of Evidence: A Systematic Review.', Journal of Services Research Policy, vol 7, no 4: $239-244$.

Kirkpatrick, S. (1995) 'Using information networks as a decision-making tool.', Journal of Health Resource Management, vol 13, no. 11:21-24.

Kothari, A., Edwards, N. (2003) 'Who Is Protecting the Canadian Public Health System?', 
Home health care practice and management, vol 15, no 5: 391-398.

Lave, J. and Wenger, E. (1991) Situated learning: Legitimate peripheral participations, New York: Cambridge University Press.

Lavis, J.N., Robertson D., Woodside, J.M., McLeod, C.B., Abelson, J. (2003) 'How can research organizations more effectively transfer research knowledge to decision-makers?', vol 81, no 2: $221-222$

Lomas, J. (2000) 'Using 'linkage and exchange' to move research into policy at a Canadian foundation.', Health affairs, vol 19, no 3: 236-240.

Muir Gray, J.A. (2004) ‘Evidence based policy making.’, BMJ, vol 329: 988-9.

Nohria, N. and Eccles, R. (1992) 'Face-to-face: making network organisations work.', in Nohria N. and Eccles R.(eds) Networks and Organisations: Structure, Form and Action, Boston, MA: Harvard Business School Press.

National Advisory Committee on SARS and Public Health (October 2003) 'Learning from SARS: Renewal in Public Health in Canada', Health Canada.

O'Carroll, P.W. and the Public Health Informatics Competency Working Group (2002) Informatic Competencies for Public Health Professionals, Seattle, WA: Northwest Center for Public Health Practice.

Patton, M. (2002) Qualitative evaluation and research methods. Newbury Park, CA: Sage.

Rogers, E.M. (1995) $\left(4^{\text {th }}\right.$ ed) Diffusion of innovations, New York, NY: Free Press.

Russell, J., Greenhalgh, T., Boynton, P., and Rigby, M. (2004) 'Soft networks for bridging the gap between research and practice.' $B M J$, vol 328, no. 7449:1174-1180.

Rynes, S.L., Bartunek, J.M., \& Daft, R.L. (2001). Across the great divide: Knowledge creation and transfer between practitioners and academics. Academy of management journal, 44, (2) 340355 .

Sackett, D.L., Richardson W.S., Rosenberg W., Haynes R.B. (1997) Evidence-based medicine: how to practice and teach EBM, London: Churchill Livingstone.

St. Croix, C. (2001). Putting Research to Work.: Current Work Place Research - a Supplement to At Work. In Focus (20, A) February ISSN \# 1261-5148 Institute of Work and Health. Retrieved on January 5, 2004 www.iwh.on.ca

Wenger, E., McDermott, R., Snyder, W. (2002) Cultivating Communities of Practice, A guide to Managing Knowledge, Boston MA: Harvard Business School Press. 
Table 1 - Geographical profile of participants

\begin{tabular}{|l|l|l|l|l|l|l|}
\hline Province & $\begin{array}{l}\text { Focus } \\
\text { Group 1 }\end{array}$ & $\begin{array}{l}\text { Focus } \\
\text { Group 2 }\end{array}$ & $\begin{array}{l}\text { Focus } \\
\text { Group 3 }\end{array}$ & Workshop & Interviews & Total \\
\hline $\begin{array}{l}\text { Newfoundland } \\
\text { and Labrador }\end{array}$ & & 1 & & 1 & 1 & 3 \\
\hline $\begin{array}{l}\text { Prince Edward } \\
\text { Island }\end{array}$ & & & & 1 & & 1 \\
\hline Nova Scotia & & 1 & 1 & 1 & & 2 \\
\hline $\begin{array}{l}\text { New } \\
\text { Brunswick }\end{array}$ & & 2 & & 1 & 2 & 5 \\
\hline Quebec & 9 & 4 & 6 & 5 & & 24 \\
\hline Ontario & 1 & & & & 1 \\
\hline Manitoba & & 1 & & 1 & 2 & 4 \\
\hline Alberta & & 2 & 2 & 1 & & 5 \\
\hline $\begin{array}{l}\text { British } \\
\text { Columbia }\end{array}$ & & 1 & 8 & 6 & 15 \\
\hline $\begin{array}{l}\text { National/ } \\
\text { Federal } \\
\text { Organizations }\end{array}$ & & 12 & 10 & 19 & 11 & 61 \\
\hline $\begin{array}{l}\text { Total \# of } \\
\text { participants }\end{array}$ & 9 & 7 & 3 & 7 & 3 & 10 \\
\hline $\begin{array}{l}\text { \# of provinces } \\
\text { represented }\end{array}$ & 1 & & & & & \\
\hline
\end{tabular}

